\title{
EKSPLORASI KECERDASAN DAYA JUANG (ADVERSITY QUOTIENT) MAHASISWA AKUNTANSI DALAM TINJAUAN FENOMENOLOGI
}

\author{
Eliza Noviriani \\ Akuntansi Keuangan Perusahaan, Politeknik Negeri Sambas \\ Jl. Raya Sejangkung, Sambas Kalimantan Barat, 79462 \\ E-mail : eliza.noviriani@poltesa.ac.id
}

\begin{abstract}
ABSTRAK
Riset ini adalah riset keperilakuan yang bermanfaat bagi pendidikan akuntansi. Tujuan dari penelitian ini yaitu eksplorasi daya juang (adversity quotient) mahasiswa ketika dihadapkan pada situasi-situasi pemicu stres karena berdasarkan hasil riset sebelumnya, mayoritas menunjukkan kecenderungan tingkat stres di kalangan mahasiswa. Kecerdasan daya juang (adversity quotient) tersebut merupakan salah satu aspek otak kanan yaitu unsur kecerdasan berlandaskan Tuhan, hati dan perasaan. Penelitian yang bersifat prediktif untuk mengetahui faktor penyebab stres mahasiswa dinilai belum lengkap. Atas dasar tersebut, peneliti menyajikan kisah daya juang mahasiswa dalam menghadapi tantangan dan peluang stres nya masing-masing dengan menggunakan salah satu metode dalam riset kualitatif yaitu metode fenomenologi transendental. Riset ini memanfaatkan hasil kuesioner dari penelitian sebelumnya yang berjudul "Academic Stress Inventory of Students at Universities and Colleges Technology" dengan informan mahasiswa Akuntansi. Hasil menunjukkan bahwa kecerdasan daya juang (adversity quotient) atau sederhana nya kemampuan individu menghadapi kesulitan berbeda antara satu dengan lain sesuai karakter individu masing-masing yaitu climbers, campers dan quitters. Tipe quitters adalah individu dengan dorongan untuk maju yang rendah dan memiliki sedikit ambisi. Tipe campers dapat didefinisikan sebagai individu yang telah berhenti bergerak maju dalam karier mereka karena mereka telah lelah dengan banyak rintangan di lingkungan dan cenderung puas dengan keadaan saat ini. Di sisi lain, tipe climbers merupakan individu yang terus mencari perbaikan dan menginginkan pertumbuhan dalam hidup nya.
\end{abstract}

Kata Kunci: Daya Juang, Adversity Quotient, Mahasiswa Akuntansi, Fenomenologi

\section{PENDAHULUAN}

Tujuan pendidikan itu untuk mempertajam kecerdasan, memperkukuh kemauan serta memperhalus perasaan, sebagaimana penuturan Tan Malaka, seseorang yang diberi gelar pahlawan nasional atas pemikiran serta peran besar nya dalam perjuangan kemerdekaan Indonesia guna menghasilkan manusia-manusia berakhlak bukan sekadar mencetak manusia-manusia "mesin" (Mulawarman, 2014; Kamayanti, 2012). Namun, bila berkaca pada realita saat ini, apakah hal tersebut sudah terwujud? Fakta nya, sistem pendidikan di Indonesia dewasa ini masih menitikberatkan pada usaha untuk mencapai kemampuan menguasai ilmu pengetahuan dengan akal logis dibandingkan mengombinasikan nya dengan unsur emosional (EQ) maupun spiritual (SQ). Bahwa, “...pendidikan telah menyeret kita pada kalkulasi rasional, bukan pada intuisi..." (Triyuwono, 2013). Ironis, keadaan semacam ini nyatanya turut terjadi dalam pendidikan tinggi akuntansi di Indonesia. Sistem pendidikan akuntansi seperti menghilangkan peran Tuhan, hati dan perasaan. Akuntansi adalah alat laksana pisau, jika digunakan secara tepat maka akan memberikan manfaat, namun bila digunakan dengan tidak semestinya boleh jadi menimbulkan mudarat. Untuk itulah hati yang berketuhanan diperlukan guna mengontrol pikiran dalam pengimplementasian ilmu akuntansi (Lusiono \& Noviriani, 2019). Namun ironis nya, Tuhan tidak pernah "tersentuh" dalam buku teks akuntansi. Padahal, seorang Luca Pacioli yang dikenal sebagai Bapak Akuntansi penemu pembukuan berpasangan (double entry bookkeeping) menuliskan "in the name of God" saat membuat laporan keuangan. Ini membuktikan bahwa memang Tuhan telah ternegasi (Kamayanti, 2012) dan perwujudan paham sekularisme (Mulawarman, 2014) pada akuntansi kini.

Ketiadaan Tuhan, hati maupun perasaan dalam sistem pendidikan akuntansi ini berdampak pada sumber daya manusia yang dihasilkan. Dewasa ini, mahasiswa cenderung sensitif terhadap tantangan dan kurang berdaya juang atas tekanan yang ia hadapi sehingga memiliki mental "gampang" menyerah. Isu kesehatan mental mahasiswa maupun siswa kini menjadi masalah utama di beberapa negara. Terdapat peningkatan jumlah mahasiswa yang sakit mental secara signifikan dimana mayoritas mencari bantuan untuk mengatasi depresi atau kecemasan.

Dapat dikatakan bahwa mahasiswa saat ini masih sebatas menguasai kecerdasan akademik, padahal diperlukan unsur kecerdasan-kecerdasan atas dasar Tuhan, hati dan perasaan untuk kesehatan mental mereka. 
Salah satu aspek otak kanan yang merupakan kecerdasan berlandaskan Tuhan, hati dan perasaan adalah kecerdasan daya juang (adversity quotient). Pengaruh yang sangat besar dari unsur daya juang terhadap kualitas lulusan perguruan tinggi (Puspitacandri, 2020; Koohbanani, Dastjerdi, Vahidi, and Far, 2013). Pribadi yang berdaya juang tinggi akan lebih mampu menghadapi tekanan di dunia kerja (Chin, Anantharaman, dan Tong, 2011).

Tidak dapat di pungkiri daya juang merupakan salah satu aspek penting dalam kehidupan yang membentuk karakter dan potensi seseorang (Mwivanda \& UoN, 2018). Teori adversity quotient ini dikemukakan oleh Paul G. Stoltz, seorang psikolog di AS, pada tahun 1997. Ia menata ulang banyak literatur sains, dan menggabungkan tiga jenis konsep ilmiah yaitu psikologi kognitif, psychoneuroimmunology dan neurophysiology. Model tersebut menunjukkan bahwa adversity quotient sangat terkait dengan keberhasilan hidup dan karier seseorang, serta reaksi individu terhadap kesulitan yang dihadapi diukur dengan angka (Shen, 2014). Adversity Quotient terdiri dari empat dimensi $\mathrm{CO}_{2} \mathrm{RE}$ yaitu: Control capability of adversity (hasil belajar berkaitan dengan usaha), $\mathrm{O}_{2}$ Origin + Ownership (mengambil tanggung jawab atas kesulitan bukannya menyalahkan diri sendiri), Reach Scope of effect of adversity on oneself, Endurance Depth and duration of frustration caused by adversity. Ketika skor lebih tinggi, artinya kemampuan merespons kesulitan juga tinggi, stres dapat dikelola dengan baik menjadi sebuah motivasi (Phoolka and Kaur, 2012; Shen, 2014).

Lebih dari sekadar menafsirkan daya juang dalam bentuk angka, penelitian ini berupaya untuk menggambarkan daya juang mahasiswa berdasarkan pengalaman mereka. Adversity quotient dapat digunakan salah satu nya memprediksi kemampuan seseorang untuk bangkit dan pulih ketika dihadapkan dengan segala sesuatu yang tidak sesuai harapan (Phoolka and Kaur, 2012).

Riset yang mengangkat topik adversity quotient sejauh ini telah banyak dilakukan. Sebut saja berbagai peneliti dalam negeri dan luar negeri (Soraya and Al Farizi (2017); Azaria and Suprihatin (2018); Chang and Wang (2017); Ajiwibawani and Subroto (2017); Mwivanda and UoN (2018); Farisuci, Budiman, and Lukmawati (2019)) dengan metode dan hasil yang bervariasi. Namun, riset-riset tersebut mayoritas adalah riset berlandaskan kuantitatif. Beberapa riset memang menggunakan metode wawancara mendalam (in depth interview) sebagai ciri khas penelitian kualitatif, tetapi sepengetahuan peneliti belum ada riset yang menggunakan paradigma fenomenologi dalam penelitian nya. Oleh karena itu, dengan tetap menggunakan dasar teori adversity quotient seperti yang telah dikemukakan di atas, tujuan utama penelitian ini adalah menggali daya juang mahasiswa dengan metode yang berbeda dari sebelum nya.

\section{RUANG LINGKUP}

Penelitian ini mengkaji stres di kalangan mahasiswa akuntansi dan kecerdasan daya juang untuk mengatasi nya. Karena keterbatasan peneliti dan agar scope penelitian lebih terfokus, wawancara tidak dilakukan untuk seluruh mahasiswa akuntansi yang menjadi responden pada kuesioner yang peneliti sebar sebelumnya. Dalam hal ini, peneliti melakukan wawancara terhadap 2 (dua) orang mahasiswa dari hasil sampling responden.

Peneliti memperluas ruang lingkup riset dari penelitian sebelumnya dengan menggunakan paradigma interpretive fenomenologi. Perbedaan dengan penelitian sebelum nya adalah pada lingkup kajian, dimana penelitian dengan paradigma positivisme/fungsionalisme menekankan pada analisis atau prediksi hubungan antar variabel dengan pertanyaan penelitian "apakah". Sedangkan paradigma interpretive lebih kepada eksplorasi pengalaman individu dengan ciri khas pertanyaan penelitian "bagaimana". Perbedaan paradigma penelitian tentu nya akan berdampak pada hasil kajian. Paradigma yang peneliti gunakan dalam riset ini akan menghasilkan gambaran realitas faktor stres yang dialami dan daya juang mahasiswa dalam menghadapi nya secara lebih nyata berdasarkan pengalaman mereka.

\section{BAHAN DAN METODE}

Kisah daya juang mahasiswa yang akan disajikan berikut ini berawal dari "kegundahan" peneliti terhadap hasil angket (kuesioner) untuk mendeteksi tingkat stres mahasiswa yang peneliti sebar kepada mahasiswa akuntansi semester satu (first year student) dan semester tujuh (last year student) di sebuah Politeknik. Mengapa mahasiswa tersebut dipilih? Alasan nya karena pada tahun pertama, mahasiswa memasuki dunia perkuliahan, yang berbeda dengan lingkungan ketika masih duduk di bangku sekolah (Augesti, Lisiswanti, Saputra, and Nisa, 2015; Geng and Midford, 2015; Mason, 2017; McCready, 2018). Fakta tersebut turut di dukung hasil kuesioner bahwa hampir sebanyak 54\% mahasiswa menyatakan bahwa terdapat perbedaan antara Politeknik dengan Sekolah Menengah Atas. Kondisi demikian tentu nya merupakan suatu perubahan besar pada hidup mahasiswa dan membutuhkan adaptasi terhadap lingkungan tersebut sehingga mahasiswa rentan mengalami stres. Sementara itu, kewajiban untuk menyelesaikan tugas akhir di samping mengikuti perkuliahan serta mengulang perkuliahan yang nilai nya belum memuaskan adalah faktor penyebab stres pada mahasiswa tingkat akhir (Augesti dkk, 2015).

Peneliti mengadaptasi angket (kuesioner) dari penelitian Lin dan Chen yang berjudul "Academic Stress Inventory of Students at Universities and Colleges Technology". Stres diklasifikasikan dalam empat kategori yaitu: memandang stres dari pengaruh eksternal, stres yang berasal dari persepsi atau evaluasi atas situasi, stres yang bersumber dari hubungan antara kebutuhan 
lingkungan dan kemampuan individu untuk memenuhi nya dan stress yang berhubungan dengan lingkungan dan individu. Berdasarkan hal tersebut, peneliti mendalami konstruk-konstruk penyebab stres melalui proses wawancara langsung. Setidaknya terdapat 7 (tujuh) faktor penyebab stres bagi mahasiswa: "The possible causes of stress that can be faced in the academic stress inventory developed for this research were: 1) Stress from teachers, 2) Stress from results, 3) Stress from test, 4) Studying in group stress, 5) Peer stress, 6) Time management stress, 7) Self-inflicted stress..."

Tujuh faktor di atas terbagi dalam beberapa item pernyataan yaitu sebagai berikut:

Factors 1: Teacher's Stress

1. I feel that the forms and content of exercises and reports of some teachers are too strict.

2. I feel that the exercises and reports of some teachers are too difficult.

3. I feel that the exercises and reports of some teachers are excessive.

4. I feel that I do not understand a lot about some teachers' teaching content.

5. Some teachers provide too much data; this causes me to be unable to finish studying and to assimilate the knowledge

6. I feel a lot of pressure because some subjects use foreign language books.

7. I feel that I am not able to adapt to some teachers' teaching methods.

8. I feel that once I got into university, I could not keep up with the speed of the teachers' instruction.

9. In some courses, I have to spend a lot of time looking for data and information.

Factors 2: Results Stress

1. I feel that my parents think that I am not serious with my studies.

2. I have conflicts with my parents due to my academic results.

3. I feel that there is vast difference between my current results and high school results.

4. I worry that my academic results will not meet my parents' expectations.

5. I feel that the results of my recent tests are imperfect and have regressed.

Factors 3: Tests Stress

1. I do not get good enough sleep at night because I worry about school tests.

2. I stay up late before all the big and small school tests.

3. I worry that I have to redo the compulsory courses in which I fail.

4. I feel that the tests and class content of some subjects are variable, which causes me to be unable to prepare adequately

Factors 4: Studying in Group Stress
1. I often face problems as to how to share work with my classmates when some exercises or reports require group work.

2. When group work is required to complete an exercise or report, I worry that I will not be able to find a suitable group member

3. When I give a speech or presentation, I worry that my classmates will laugh at my inability to perform well.

4. Sometimes, the words used by my classmates easily hurt my self-esteem or cause harm.

5. I feel nervous when I need to make a speech or give a presentation.

Factors 5: Peer Stress

1. When I want to study on my own, I am often affected by my classmates' chatting.

2. I feel that my classmates are very noisy during class and this influences my class situations

3. I feel that there is open strife and veiled struggles among classmates due to academic performance

4. I am very worried that my academic results are not as good as those of my classmates are.

Factors 6: Time Management Stress

1. I feel that I am not able to adjust and schedule the time between academic and social activities effectively.

2. I feel that it is very difficult for me to find a balance between my academic and social activities.

3. I feel that the social activities and student association affect my academic work.

Factors 7: Self-Inflicted Stress

1. I feel that my learning level is not as good as that of my classmates.

2. Ifeel that I have so many courses that I am out of breath.

3. I feel that I have no interest in some subjects or academics.

4. I feel that after I entered university, my performance was not as good as I had expected.

Hasil yang peneliti dapatkan sungguh mengejutkan. Dari 143 kuesioner (88 kuesioner mahasiswa semester 1 dan 55 kuesioner mahasiswa semester 7) mayoritas menunjukkan adanya kecenderungan tingkat stres di kalangan mahasiswa. Tingkat stres terbesar berada pada faktor studying in group stress, peer stress serta selfinflicted stress. Artinya, stres yang dialami oleh mahasiswa dipengaruhi oleh lingkungan sekitar dan kepercayaan diri. Stres yang berasal dari tenaga pendidik (teacher's stress) maupun stres yang disebabkan hal-hal bersifat akademik (results stress dan tests stress) justru lebih rendah. Kontradiktif dengan hasil tersebut, mahasiswa justru merasa tidak mengalami kesulitan dalam menyeimbangkan kegiatan sosial maupun organisasi nya. Menelisik fakta tersebut, kira nya dapat dinyatakan bahwa stres yang dialami mahasiswa berasal 
dari beberapa faktor baik lingkungan sekitar (tenaga pendidik dan teman sekelas), kepercayaan diri serta sisi akademik. Tentu nya hal ini perlu menjadi perhatian penting khusus nya bagi tenaga pendidik. Tak terbantahkan, stres berpengaruh terhadap mental dan aktivitas studi mahasiswa (Geng and Midford, 2015); Mason, 2017; McCready, 2018). Pendidikan tidak boleh hanya berfokus pada penyampaian teori melalui transfer ilmu pengetahuan, namun lebih dari itu, pendidikan adalah bentuk penyampaian ilmu yang holistik meliputi nilai-nilai pengetahuan, etika, kemandirian, kemampuan mengontrol diri hingga kemanusiaan, sebagaimana pernyataan Chang and Wang (2017):

\section{"Education should include the following goals: to develop good attitudes, self-development, from the creation, know yourself, develop relationships and cultivate emotions, imagination and gaining capabilities".}

Menurut peneliti, belum lah dikatakan lengkap jika penelitian hanya sampai pada mengetahui faktor penyebab stres mahasiswa. Solusi nya, peneliti perlu menggali lebih dalam mengenai bagaimana sesungguhnya stres yang mereka alami serta daya juang mereka melalui penelitian dengan metode kualitatif paradigma interpretive fenomenologi. Dengan kata lain, eksplorasi tentang daya juang (adversity quotient) mahasiswa ketika dihadapkan pada situasi-situasi pemicu stress perlu dilakukan. Uraian sebentuk kisah para pejuang inilah yang akan kita temukan dalam tulisan ini.

Hasil penggalian daya juang mahasiswa ini dituangkan dalam sebuah tulisan dengan berlandaskan pada paradigma interpretive. Menurut Triyuwono (2013):

"Para ahli mengklasifikasikan paradigma yang dapat digunakan sebagai pendekatan penelitian dalam beberapa kategori, diantaranya Burrell \& Morgan merumuskan empat paradigma yaitu paradigma positivisme, interpretive, radikal humanist dan radikal structuralise. Selanjutnya, Chua menyederhanakan pembagian paradigma tersebut menjadi tiga paradigma yaitu paradigma positivisme, interpretive dan kritis. Sarantakos menggolongkan empat paradigma yaitu fungsionalisme, interpretive, kritis dan postmodern. Sementara itu, ada paradigma lain yang melengkapi keempat paradigma diatas yaitu paradigma spiritualise."

Paradigma interpretive lebih menekankan pada makna atau interpretasi seseorang terhadap sebuah simbol. Tujuan penelitian dalam paradigma ini adalah memahami atau memaknai dan kemudian menginterpretasikan pemaknaan tersebut dan bukan menjelaskan atau memprediksi suatu hubungan sebagaimana tujuan paradigma positif/fungsionalis. Paradigma ini memfokuskan pada pemahaman mengenai dunia yang diciptakan secara subjektif apa adanya.
Intinya, untuk memahami dan mengeksplorasi daya juang (adversity quotient) mahasiswa, tidak lah cocok jika penelitian ini menggunakan paradigma positif yang sebatas memprediksi hubungan dan pengaruh antar variabel. Paradigma yang sesuai adalah paradigma interpretive yang dapat menggali pengalaman atas daya juang masing-masing informan yang mengalami situasi tersebut dengan melakukan interaksi langsung dua arah.

Dalam fenomenologi transendental segala informasi bebas dari persepsi atau pemikiran penulis sehingga segala sesuatu harus berdasarkan pengalaman informan. Hal ini sesuai pada konsep Husserl, yakni epoche (bracketing) yang membutuhkan eliminasi atas prasangka atau ego dan pengetahuan terdahulu peneliti sehingga fenomena yang dituturkan bebas campur tangan peneliti dan murni pengalaman dari informan (Creswell \& Creswell, 2017). Menggunakan fenomenologi transendental, peneliti mengeksplorasi fenomena berdasarkan kesadaran individu (Lusiono and Noviriani, 2019; Noviriani, Ludigdo, and Baridwan, 2015). Berdasarkan interaksi dengan informan, peneliti menginterpretasikan tindakan sosial daya juang (adversity quotient) mahasiswa sebagai sesuatu yang bermakna (dimaknai) serta merekonstruksi kembali turunan makna dari tindakan yang bermakna tersebut. Perlu digarisbawahi, dalam proses transfer pengalaman dan pengetahuan dengan pendekatan fenomenologi transendental ini peneliti menghindari keterlibatan pemberian informasi maupun pengetahuan dalam bentuk apapun untuk mencegah bias sehingga fenomena tersebut benar-benar pengalaman yang dirasakan informan. Dalam hal ini, peneliti tidak menyampaikan informasi, pengetahuan dan ide apapun yang dapat mengarahkan/menggiring pengalaman mahasiswa tentang daya juang mereka.

Terdapat beberapa tahapan sistematis analisis data dalam fenomenologi transendental (Creswell \& Creswell, 2017) Dimana metode fenomenologi transendental meliputi empat fase perenungan yaitu: epoche, reduksi fenomenologi, variasi imajinatif dan sintesis antara makna dan esensi: Epoche: Epoche adalah pemutusan hubungan dengan pengalaman dan pengetahuan yang kita yakini sebelumnya. Epoche membuat kita masuk ke dalam dunia internal yang murni, sehingga memudahkan untuk pemahaman akan diri dan orang lain. Reduksi fenomenologi: Ketika epoche adalah langkah awal untuk memurnikan objek dari pengalaman dan prasangka awal, maka tugas dari reduksi fenomenologi menjelaskan dalam susunan bahasa bagaimana objek itu terlihat. Reduksi akan membawa kita kembali pada bagaimana kita mengalami sesuatu. Memunculkan kembali asumsi awal dan mengembalikan sifat-sifat alamiah nya. Variasi imajinasi: Setelah reduksi fenomenologi, variasi imajinasi muncul untuk mencari makna-makna yang mungkin dengan memanfaatkan imajinasi, kerangka rujukan, pemisahan dan pembalikan, serta pendekatan terhadap fenomena dari perspektif, posisi, peranan, dan 
fungsi yang berbeda. Tujuannya adalah untuk mencapai deskripsi struktural (structural description) dari sebuah pengalaman (bagaimana fenomena berbicara mengenai dirinya). Sintesis Makna dan Esensi: Tahap terakhir dalam penelitian fenomenologi transendental adalah integrasi intuitif dasar-dasar deskripsi tekstural dan struktural ke dalam satu pernyataan yang menggambarkan hakikat fenomena secara keseluruhan.

Sumber data utama berupa kata-kata dan tindakan diperoleh melalui pengamatan (observasi), wawancara serta dialog dengan 3 (orang) informan yang merupakan mahasiswa akuntansi. Wawancara yang dilakukan adalah jenis wawancara mendalam (in-depth interview). Wawancara secara mendalam merupakan salah satu teknik pengumpulan data yang disarankan dalam penelitian fenomenologi. Data are collected from the individuals who have experienced the phenomenon. Often data collection in phenomenological studies consists of in-depth interviews and multiple interviews with participants (Creswell \& Creswell, 2017)

Salah satu hal yang sering ditemui dalam pelaksanaan metode wawancara mendalam (in-depth interview) adalah informan tidak bersedia jika identitas nya dicantumkan. Hal ini mengingat saat proses wawancara seringkali pengalaman-pengalaman "terdalam" terungkap. Oleh sebab itu, peneliti menggunakan teknik pseudonym yang mengharuskan peneliti secara sistematis mengubah nama asli setiap subjek menjadi nama samaran atau case number saat melaporkan data (Lune \& Berg, 2017). Hal ini dimaksudkan untuk menjaga kerahasiaan identitas informan serta menghindari kekhawatiran informan karena identitasnya telah dipublikasi agar informan tidak keberatan untuk memberikan informasi penting selama penelitian berlangsung (Gerrard, 2018). Oleh sebab itu, peneliti tidak menggunakan nama asli informan melainkan nama samaran. Peneliti melakukan wawancara dengan tiga orang informan, masing-masing satu orang mahasiswa semester 1 dan dua orang mahasiswa semester 7 .

Pemilihan informan dilakukan secara tidak terencana saat para informan pada awal nya menemui peneliti untuk bercerita mengenai masalah yang mereka alami. Berdasarkan penuturan mereka, kendala terbesar dalam mengikuti perkuliahan selama ini adalah faktor-faktor stres seperti yang telah disebutkan di atas. Atas dasar itu, peneliti beranggapan bahwa para informan dapat menjadi informan kunci dalam riset ini.

\section{PEMBAHASAN}

Bagian ini mengisahkan dua cerita dengan alur yang berbeda dari dua orang informan sebut saja Bang $\mathrm{Z}$ mahasiswa semester 1 dan Kak D mahasiswa semester 7. Seperti yang telah disebutkan di atas, Pemilihan informan ini dilakukan secara tidak sengaja karena pada awalnya kedua informan menemui peneliti untuk sekadar mencurahkan isi hati. Setelah melalui pengamatan mendalam maka diputuskan kedua mahasiswa ini menjadi informan dalam penelitian. Tentu nya, kisah mereka dimuat setelah peneliti meminta izin untuk menuliskannya dengan nama samaran.

\subsection{Hasil Wawancara dan Analisis Tipe Climbers}

"Saya akhiri perkuliahan kita hari ini, untuk selanjutnya sampai bertemu minggu depan. Terima kasih, Assalamualaikum wr wb..." Demikian kata penutup saya saat mengakhiri kelas Akuntansi Dasar I di Semester 1. Kata "saya" di sini menunjukkan penekanan pada subjektivitas dalam penelitian. Hal ini diperbolehkan karena berbeda dengan penelitian positivistik yang menjunjung tinggi objektivitas, paradigm non positivistik tidak terlepas dari unsur subjektivitas peneliti (Creswell, 2014).

Baru saja beranjak dari kursi dan ingin membuka pintu, sontak terdengar seseorang mahasiswa memanggil. "Bu, sibuk tidak, bisa saya ketemu ngobrol?" Sejujurnya, mahasiswa tersebut memang menarik perhatian saya di kelas karena "agak" berbeda dengan teman-teman nya yang lain. Singkat cerita, dikarenakan memang pada saat itu jadwal saya kosong, maka saya bersedia untuk ngobrol dengan sebut saja Bang Z.

Saat telah berada di ruangan...

"Sebenarnya saya tidak nyaman Bu". Bang Z buka suara. Seketika saya merasa bahwa apa yang dirasakan oleh mahasiswa tersebut berkaitan dengan perkuliahan. "Tidak nyaman kenapa?" tanya saya. "Gimana ya Bu, saya ngerasa kalau saya tidak punya teman ngobrol yang nyambung di sini. Teman-teman seperti tidak satu frekuensi." Mendengar ini saya diam sejenak. Memang jika diperhatikan secara saksama ketika di kelas mahasiswa ini memiliki pemikiran yang dewasa, cenderung kritis dan penuh rasa ingin tahu. Tidak segan dan canggung bertanya (dengan sopan tentu nya) ketika materi masih disampaikan. Terkadang hal ini menjadi bahan ejekan sekelas karena menganggap ia sok pintar. Jadi, saya tidak terkejut jika dia merasa dia kurang nyambung dengan teman yang lain. Pada saat ini, saya membuat kesimpulan pertama bahwa ada kecenderungan stres karena teman sekelas.

Selanjutnya, saya mencoba "menyentuh" pembahasan keluarga." Kalau di rumah, siapa yang sering kamu ajak ngobrol?". Bang Z menjawab "Di rumah saya cuma akrab sama kakak $\mathrm{Bu}$, saya 3 bersaudara. Itu juga tidak sering ngobrol". Selanjutnya dengan hati-hati saya menyambung "Maaf ya, kalau orang tua, masih lengkap?". Bang Z mengatakan bahwa ia hanya memiliki Ayah sementara sang Ibu sudah lama meninggal. karena Ayah dan kedua saudara nya memiliki kesibukan, Bang Z lebih sering menghabiskan waktu nya di kamar untuk bermain komputer. Pada saat ini, saya membuat kesimpulan kedua bahwa kemungkinan potensi stres karena kondisi keluarga.

Menarik, ketika sampai pada bagian ini Bang $\mathrm{Z}$ dengan bersemangat bercerita kepada saya...

"Saya sebenarnya suka sekali otak-atik software bu. Saya dulu jurusan IPA waktu SMA. Mau kuliah diluar tetapi tidak dapat izin dari orang tua dan kakak. Disuruh 
masuk Akuntansi di Sambas saja kata nya”. Bang Z kemudian melanjutkan "Ibu tau hacker kan? Saya sampai baca-baca dan tertarik bergabung komunitas $\mathrm{Bu}$, kayak Agen gitu lah bu, hehehe" "Oh ya? Ternyata menarik sekali hobi kamu ya" Ujar saya. Selanjutnya, dia masih excited menceritakan minat nya yang "berbau" spionase, CIA dan sejenisnya. Setelah beberapa saat kemudian, saya mencoba bertanya kepada Bang Z...

"Kamu merasa tertekan? Apakah hal ini jadi menghambat kamu?" Tutur saya." Sebenarnya tidak juga bu, Yah, walaupun tidak nyaman tetapi saya tidak sampai merasa terlalu gimana-gimana. Saya masih bisa lah menjalani nya Bu" Bang $\mathrm{Z}$ menambahkan hal ini mungkin dikarenakan ia sudah terbiasa mandiri sehingga merasa tidak terlalu bermasalah. Menurut Bang $\mathrm{Z}$ kemudian, namun sesekali ia butuh teman yang bisa ia ajak bertukar pikiran, berdiskusi atau paling tidak mendengarkan keluh kesah nya. Hal ini wajar mengingat sebagai makhluk sosial, seorang manusia tidak terkecuali Bang $\mathrm{Z}$ perlu berinteraksi dengan orang lain untuk memenuhi kebutuhan sosial nya tersebut.

"Tidak kah kamu merasa "dikucilkan" di kelas?" Dengan santai Bang Z menjawab "Kalau teman-teman sering ejek waktu saya tanya ke dosen itu ya saya anggap mereka yang memang takut $\mathrm{Bu}$, soalnya mereka kan tidak mau nanya. Saya pun tidak nyambung juga sama mereka". Memang, pertanyaan-pertanyaan yang diungkapkan oleh Bang $\mathrm{Z}$ di kelas (peneliti mengajar mata kuliah Akuntansi Dasar I di kelas nya) tergolong pertanyaan tingkat tinggi. "Lalu kalau tentang materi perkuliahan, ada masalah tidak? Tanya saya lagi. Bang $\mathrm{Z}$ menjawab bahwa pada awalnya mengalami kesulitan untuk memahami materi terutama mata kuliah Akuntansi Dasar I karena pada saat di SMA bukan merupakan pelajaran wajib di jurusan yang ia pilih. Namun, seiring berjalannya waktu dan banyak bertanya maka sedikit demi sedikit ia mulai bisa memahami materi yang disampaikan dosen. Di akhir pembicaraan ia menyampaikan "Terima kasih Ibu mau mendengarkan saya. Saya bukan tidak mampu tetapi hanya perlu teman untuk bertanya, bertukar pikiran dan memberikan saya nasihat".

\subsection{Hasil Wawancara dan Analisis Tipe Quitters}

"Ada apa?" Saya buka kalimat. Seketika Kak D menangis sesengggukan. Saya memberi waktu agar ia dapat menenangkan diri sejenak. Setelah ia mulai mengendalikan emosi nya ia berkata "Saya pengen pindah kelas, boleh Bu?" dengan penasaran saya bertanya alasan yang mendasari keinginan ia untuk pindah kelas padahal ia sudah berada di semester 7 yang artinya hampir menyelesaikan studi. Kak D mengatakan bahwa teman-teman sekelas nya terkesan tidak menyukai keberadaan nya Menurut Kak D, teman-teman nya tersebut seringkali sengaja menyindir dan memperolok nya. Bahkan Kak D tidak dimasukkan ke dalam grup Whatsapp kelas.
"Menurut kamu kenapa kira-kira mereka begitu?" Tutur saya. Akhirnya Kak D bercerita bahwa hal tersebut mungkin terjadi dikarenakan Kak D dianggap menjadi anak emas dalam sebuah organisasi mahasiswa di kampus. Kak D mengatakan bahwa ada sekelompok mahasiswa di kelas yang tidak suka Kak D sering diikutsertakan dalam kegiatan kepanitiaan. Padahal menurut Kak D "Saya gak ada rayu atau apa-apa Bu, saya juga gak tau kenapa sering terpilih dalam kepanitiaan". Pada saat itu, tanpa perlu bertanya lebih mendalam saya memahami bahwa lingkungan yaitu teman sekelas adalah faktor pemicu stres yang dialami oleh Kak D.

Lebih lanjut saya bertanya "Lalu apa tindakan kamu atas perlakuan teman-teman itu?" sambil menahan air mata dengan perlahan Kak D menjawab "Saya diam saja bu, saya yakin Allah yang tau sebenarnya. Tetapi kalau bisa, saya mau menjaga jarak dengan teman-teman sekelas." Tindakan Kak D ini telah saya prediksi karena karakter Kak D di kelas adalah karakter yang cenderung lebih pendiam dan tenang, sehingga perlawanan yang dia berikan atas tindakan teman-teman nya bukan bentuk perlawanan langsung tetapi dengan menghindar.

"Apakah perlakuan teman-teman selama ini berdampak ke perkuliahan kamu?" sambung saya. Kak D menjawab "Dampak pasti ada $\mathrm{Bu}$, saya jadi tidak semangat masuk, tetapi saya tetap mencoba mempertahankan nilai-nilai saya." (Hal ini sesuai dengan realita bahwa tingkat kehadiran Kak D di kelas semakin menurun, padahal Kak D tergolong mahasiswa yang berprestasi dan sejauh ini dapat menyeimbangkan kegiatan akademik serta organisasi dengan baik).

Saya menarik napas sejenak, bullying... di Negaranegara maju telah menjadi isu penting dan mendapatkan perhatian pemerintah. Para pelaku bullying akan diancam dengan sanksi yang tegas karena tergolong kejahatan pembunuhan mental. Di Indonesia? Hal ini masih dianggap kenakalan biasa, suatu bentuk canda padahal berujung kejahatan karena dapat merusak hidup seseorang. Singkat cerita, saya menyarankan kepada Kak D agar tetap berusaha untuk mengikuti perkuliahan semaksimal mungkin, dengan menguatkan hati nya bahwa dia tidak sendiri, banyak kebaikan dan potensi yang ada di dalam diri nya. Semoga Kak D dapat terus berjuang. (Sampai dengan hari ini Kak D masih sering bertemu saya untuk sekadar bercerita dan mengungkapkan perasaannya. Walaupun sudah jauh lebih membaik dan termotivasi, namun Kak D tetap perlu bimbingan dan pendampingan untuk memulihkan kesehatan mental nya).

Berdasarkan kisah yang dituturkan kedua informan di atas, dapat dinyatakan bahwa terdapat perbedaan sikap pada saat masing-masing individu menghadapi kesulitan atau tantangan. Hal ini menunjukkan bahwa tingkat kecerdasan daya juang (adversity quotient) setiap orang tidak sama. Adversity quotient menggambarkan tiga jenis individu, yaitu: Climbers, Campers dan Quitters (Shen, 2014). Menurut teori, Quitters adalah individu dengan 
dorongan minimal dan sedikit ambisi. Mereka jarang kreatif, tidak suka mengambil risiko dan cenderung menghindari tantangan. Campers dapat didefinisikan sebagai individu yang telah berhenti bergerak maju dalam karier mereka karena mereka telah lelah dengan banyak rintangan di lingkungan saat ini. Dengan demikian, mereka telah menerima apa yang mereka anggap cukup baik, jarang menghadapi tantangan yang lebih besar. Oleh karena itu mereka puas dengan keadaan saat ini dan membiarkan peluang yang lebih besar berlalu begitu saja. Di sisi lain, Climbers merupakan individu yang terus mencari perbaikan dan pertumbuhan. Mereka hidup untuk mendapatkan yang terbaik dari kehidupan, memiliki motivasi diri dan sangat terdorong untuk maju".

Bang $\mathrm{Z}$ merupakan individu yang tergolong ke dalam tipe climbers. Pada awalnya ia menuturkan bahwa ia sedang dalam kondisi tidak nyaman, namun setelah di telisik lebih lanjut, ketidaknyamanan yang ia rasakan tidak menjadi penghambat ia untuk menjalani perkuliahan, melalui pernyataan-pernyataan nya tercermin sikap tidak peduli dengan penilaian orang lain. Ia cenderung menjalani kehidupan dengan cara nya dan mencari kebahagiaan dengan jalan nya. Individu dengan tipe daya juang seperti ini berhasil mengatasi tantangan yang berpeluang menjadi penghambat serta memiliki kekuatan dan motivasi dari diri sendiri.

Sementara itu, jika merujuk pada tipe adversity quotient ini maka Kak D dapat digolongkan ke dalam individu dengan tipe quitters. Tanpa perlu bertanya lebih jauh apakah ia tertekan atau stres, dari gestur, mimik muka dan pernyataan Kak D tersirat menyerah atas kesulitan yang sedang ia hadapi. Ia lebih memilih untuk membiarkan kesulitan tersebut menguasai diri nya sehingga membuat ia seakan-akan "terusir" dari jiwa nya. Kak D menyebutkan "Tuhan” dalam penuturannya. Hal ini menunjukkan bahwa tipe quitters cenderung menghindari kesulitan dan menyerahkan keadaan pada Tuhan dengan harapan dan kepercayaan bahwa Tuhan lah yang dapat menyelesaikan persoalan mereka.

Penanganan terhadap berbagai tipe daya juang ini tentu nya bervariasi dan tidak dapat disamaratakan. Dr. Stoltz mengemukakan beberapa langkah yang dapat dilakukan untuk meningkatkan daya juang. Langkahlangkah ini disebut LEAD yaitu sebagai berikut (Phoolka \& Kaur, 2012):

1. Listen. Mendengarkan respons daya juang pribadi dan orang lain kemudian mengukur bagaimana respons tersebut terhadap suatu situasi.

2. Explore. Mengeksplorasi penyebab atau sumber respons.

3. Analyse. Menganalisis fakta yang menunjukkan bahwa memang pribadi atau orang tersebut tidak memiliki kendali atas sebuah situasi, apakah hal tersebut berlangsung selama nya dan mempengaruhi kehidupan.

4. Do. Lakukan sesuatu untuk mengatasi kendala.
Berdasarkan hal-hal diatas, kunci utama adalah mendengarkan. Dengan mendengarkan kita, dalam konteks sebagai tenaga pendidik tahu masalah apa yang mereka hadapi dan rasakan. Untuk tipe climbers misalnya, mereka butuh sosok seseorang yang selalu hadir, sehingga ketika pada satu waktu mereka lemah, merasa sedang tertekan, tidak ada celah untuk terpuruk. Melalui dukungan tersebut, mereka dapat kembali kuat dan bahkan lebih kuat untuk menjalani perkuliahan. Sedangkan individu quitters atau campers memerlukan dukungan sepenuh hati karena mereka adalah individu yang belum percaya bahwa diri mereka sendiri dapat menghadapi tantangan. Setelah mendengarkan dan tahu apa kendala sesungguhnya yang dihadapi mahasiswa, tenaga pendidik dapat mengeksplorasi dan menganalisis penyebab hingga dampak tinggi atau rendah nya daya juang terhadap perkuliahan mereka. Selanjutnya, tenaga pendidik dapat memberikan solusi untuk meningkatkan daya juang tersebut agar perkuliahan mereka dapat berjalan dengan lancar.

Mahasiswa dengan dukungan tenaga pendidik juga selayaknya dapat memaksimalkan potensi otak kanan untuk mendukung kemampuan intelektual yang mereka miliki. Dukungan yang dapat dilakukan tenaga pendidik adalah dengan lebih mendengarkan, mengeksplorasi, menganalisis dan memberikan solusi kepada mahasiswa. Tenaga pendidik sejati nya memiliki kemauan untuk membantu mahasiswa mengatasi kendala dalam perkuliahan yang menjadi sumber stres bagi mereka. Karena terbukti, banyak sumber stres yang dapat menjadi penyebab kegagalan perkuliahan.

\section{KESIMPULAN}

Hasil riset pada mahasiswa akuntansi dengan menggunakan metode fenomenologi menggambarkan dua tipe kepribadian yang berbeda yaitu quitters dan climbers. Artinya, kemampuan daya juang dalam mengelola stres juga berbeda. Perbedaan perlakuan mahasiswa saat menghadapi kesulitan seperti yang telah disebutkan di atas, sekali lagi menunjukkan perbedaan daya juang individu. Namun bagaimana pun bentuk nya, daya juang yang mereka tunjukkan pada dasarnya melibatkan unsur Tuhan, hati dan perasaan. Hal ini terlihat pada kemampuan mereka untuk mengontrol diri dan mengatasi tantangan yang merupakan sumber stres mereka. Tanpa kemampuan ini, mereka tidak akan dapat melanjutkan perkuliahan hingga saat ini.

Riset ini dapat menjadi bahan renungan bagi para pendidik. Tidak dapat terbantahkan, peran pendidik dalam perkuliahan atau pendidikan akuntansi dinilai cukup penting untuk mendampingi mahasiswa dalam mengelola potensi stres mereka. Pendidik tidak hanya memfokuskan pengajaran untuk mengejar kemampuan intelektual mahasiswa, namun lebih dari itu menjadi sosok yang membuat mereka cerdas untuk berjuang mengatasi kesulitan nya. Kesimpulannya, mereka membutuhkan dukungan bukan penghakiman apalagi hujatan dari orang yang mendidik mereka. 


\section{SARAN}

Penelitian selanjut nya dapat memperluas informan penelitian agar hasil yang didapatkan lebih bervariasi sehingga eksplorasi daya juang mahasiswa dengan berbagai karakter dapat dilakukan dengan lebih mendalam. Penggunaan program NVIVO pada penelitian dengan jenis riset kualitatif dapat dijadikan pilihan selanjutnya karena metode ini memberikan solusi untuk mengatasi subjektivitas yang menjadi masalah umum dalam penelitian kualitatif. Lebih lanjut, pendekatan mixed method dengan mengombinasikan metode kualitatif dan kuantitatif juga dapat digunakan sehingga hasil riset yang didapatkan lebih menyeluruh.

\section{DAFTAR PUSTAKA}

Ajiwibawani, M. P., \& Subroto, W. T. 2017. The Effect of Achievement Motivation, Adversity Quotient, and Entrepreneurship Experience on Students Entrepreneurship Attitude. International Journal of Academic Research in Business and Social Sciences, 7(9), 441-450.

Augesti, G., Lisiswanti, R., Saputra, O., \& Nisa, K. 2015. Differences in stress level between first year and last year medical students in medical faculty of Lampung University. Jurnal Majority, 4(4).

Azaria, U. N., \& Suprihatin, T. 2018. Adversity Quotient Pada Siswa Homeschooling. Proyeksi: Jurnal Psikologi, 12(2), 79-86.

Chang, H.-J., \& Wang, W. 2017. Comparisons of students' stress source in different countries. WSEAS Trans. Adv. Eng. Educ, 14, 9-17.

Chin, S. T. S., Anantharaman, R., \& Tong, D. Y. K. 2011. The roles of emotional intelligence and spiritual intelligence at the workplace. Journal of Human Resources Management Research, 2011, $1-9$.

Creswell, J. W., \& Creswell, J. D. 2017. Research design: Qualitative, quantitative, and mixed methods approaches: Sage publications.

Farisuci, R. M., Budiman, B., \& Lukmawati, L. 2019. Motivasi Berprestasi Dengan Adversity Quotient Pada Siswa Madrasah Aliyah Di Kota Palembang. Psikis: Jurnal Psikologi Islami, 5(1), 74-82.

Geng, G., \& Midford, R. 2015. Investigating first year education students' stress level. Australian Journal of Teacher Education (Online), 40(6), 112.

Gerrard, Y. 2018. Beyond the hashtag: Circumventing content moderation on social media. New Media \& Society, 20(12), 4492-4511.

Kamayanti, A. 2012. Cinta: Tindakan Berkesadaran Akuntan (Pendekatan Dialogis Dalam Pendidikan Akuntansi). Simposium Nasional Akuntansi XV.
Koohbanani, S. E., Dastjerdi, R., Vahidi, T., \& Far, M.H. G. 2013. The relationship between spiritual intelligence and emotional intelligence with life satisfaction among birjand gifted female high school students. Procedia-Social and Behavioral Sciences, 84, 314-320.

Lune, H., \& Berg, B. L. 2017. Qualitative research methods for the social sciences: Pearson.

Lusiono, E. F., \& Noviriani, E. 2019. Menumbuhkan Jiwa Sherlock Holmes Seorang Calon Akuntan. Journal of Applied Accounting and Taxation, 4(1), 28-38.

Mason, H. D. 2017. Stress-management strategies among first-year students at a South African University: A qualitative study. Journal of Student Affairs in Africa, 5(2), 131-149.

McCready, K. 2018. Anxiety and Stress in First Year University Students.

Mulawarman, A. D. 2014. Nyanyian Metodologi Akuntansi Ala Nataatmadja: Melampaui Derridian Mengembangkan Pemikiran Bangsa "Sendiri". Jurnal Akuntansi Multiparadigma, 4(1), 149-164.

Mwivanda, M., \& UoN, P. K. 2018. Effects of Teachers Adversity Quotient on student academic Performance in Public Secondary Schools in Kenya. International Journal of Education and Social Science, 5(11).

Noviriani, E., Ludigdo, U., \& Baridwan, Z. 2015. Studi Fenomenologi Atas Dilema Etis Auditor Internal Pemerintah. EKUITAS (Jurnal Ekonomi dan Keuangan), 19(2), 217-240.

Phoolka, E. S., \& Kaur, N. 2012. Adversity Quotient: A new paradigm to explore. Contemporary Business Studies, 3(4), 67-78.

Puspitacandri, A. 2020. The Effects of Intelligence, Emotional, Spiritual and Adversity Quotient on the Graduates Quality in Surabaya Shipping Polytechnic. European Journal of Educational Research, 9(3), 1075-1087.

Shen, C.-Y. 2014. The Relative study of gender roles, and job stress and adversity quotient. Journal of Global Business Management, 10(1), 19.

Soraya, S., \& Al Farizi, Z. 2017. Pemilihan Karir Perempuan Sebagai Akuntan Pendidik Dalam Perspektif Simone de Beauvoir: Studi Kasus pada Akuntan Pendidik Jurusan Akuntansi Fakultas Ekonomi dan Bisnis Universitas Tanjungpura Pontianak. Jurnal Ekonomi Bisnis dan Kewirausahaan (JEBIK), 5(3), 216-236.

Triyuwono, I. 2013. Makrifat Metode Penelitian Kualitatif dan Kuantitatif untuk Pengembangan Disiplin Akuntansi. Simposium Nasional Akuntansi Syariah.(September), 1-12. 